\title{
Comunicación
}

\section{IDENTIFICACIÓN DE Salmonella sp. EN TORTUGAS MOTELO (Geochelone denticulata) DE UN CRIADERO DE LA CIUDAD DE IQUITOS}

\author{
Identification of Salmonella SPP. in Motelo Turtles (Geochelone \\ denticulata) of A Zoo Farm in Iquitos City
}

\author{
Nelson Ruiz M. ${ }^{1}$, Sonia Calle E. ${ }^{1,2}$, Hugo Gálvez C. ${ }^{3}$
}

\section{Resumen}

El objetivo del presente estudio fue detectar la presencia de Salmonella sp. en 30 tortugas motelo (Geochelone denticulata) de un zoocriadero de la zona de Iquitos, Perú. Las muestras de heces se obtuvieron por hisopado rectal y se procesaron mediante pruebas de cultivo bacteriológico y bioquímicas. El 6.7\% de las muestras fueron positivas a Salmonella sp., donde de la tipificación dio como resultado Salmonella enterica subespecie enterica serotipo typhimurium.

Palabras clave: Salmonella, tortugas motelo, enterobacterias, tipificación

\section{Abstract}

The objective of the present study was to detect the presence of Salmonella spp. in 30 motelo turtles (Geochelone denticulata) in a zoo of the Iquitos region, Peru. Fecal samples were obtained by rectal swaps and processed by bacteriological and biochemical cultivation tests. The results showed that $6.7 \%$ of the samples were positive to Salmonella spp. and the typing indicated Salmonella enterica subspecies enterica serotype typhimurium.

Key words: Salmonella, motelo turtle, enterobacterias, typing

\footnotetext{
${ }^{1}$ Laboratorio de Microbiología y Parasitología Veterinaria, ${ }^{3}$ Estación Experimental del Centro de Investigaciones IVITA-Iquitos, Facultad de Medicina Veterinaria, Universidad Nacional Mayor de San Marcos, Lima

${ }^{2}$ E-mail: calleson@gmail.com
} 
Salmonellas causantes de enfermedades infecciosas son un importante problema de salud animal y pública (Wray et al., 1993). Todas las especies de salmonellas representan un riesgo ocupacional para los médicos veterinarios, ocasionando afecciones como la enterocolitis y la infección septicémica (Bradley et al., 2001). Asimismo, un gran número de especies de animales, incluyendo animales silvestres criados en zoológicos o laboratorios, han sido investigadas como potenciales reservorios de salmonella (Monzón et al., 1995).

La presencia de salmonella en órganos internos de reptiles que muestran signos clínicos está generalmente asociada con factores predisponentes, tales como estados de estrés, carga parasitaria, traumas, tumores, enfermedades infecciosas (Pasmans et al., 2003). Los serovares de Salmonella enterica muestran una adaptación a los reptiles pero conservando su patogenicidad para animales de sangre caliente; sin embargo, también existen cepas invasivas de Salmonella enterica subespecie enterica que han sido aisladas de cocodrilos (Pasmans et al., 2000; Corrente et al., 2004). Salmonella está en la flora normal del intestino de tortugas, pudiendo representar una importante fuente de infección zoonótica a los seres humanos (Pasmans et al., 2002).

La incidencia de salmonella en tortugas ha sido el tema de extensas investigaciones, ya que son comúnmente usados como mascotas (Strohl et al., 2004), y reportadas como responsables de salmonelosis en humanos, especialmente en niños; sin embargo, no existen trabajos definitorios sobre el rol que juegan los reptiles de vida libre así como en cautiverio en la transmisión de salmonelosis (Hidalgo-Vila et al., 2007).

Es así que el presente estudio se abocó a la detección de Salmonella sp. en tortugas motelo (Geochelone denticulata) mediante caracterización bioquímica, así como a la tipificación para identificación del serotipo. El estudio se realizó en un zoocriadero parti- cular ubicado en el caserío Cruz del Sur, Km 8 de la carretera Iquitos - Nauta, Loreto entre junio y julio de 2007. El zoocriadero tenía 30 tortugas motelo (Geochelone denticulata); de estas, 22 eran hembras jóvenes y ocho machos (6 adultos de 7 años y 2 jóvenes). El sexo se reconoce por la forma de la parte ventral del caparazón.

Las tortugas estaban en un área cercada de $25 \mathrm{~m}^{2}$, construido con materiales de la zona y piso de tierra. La alimentación era a base de frutas y verduras y con agua $a d$ libitum. Algunas tortugas, aparentemente normales, presentaron historia de evacuaciones frecuentes de diarrea de aspecto verdoso, fétidas, mucoides y, en ocasiones, con estrías de sangre. La fuente de agua era una pequeña laguna alimentada con agua de lluvia, que podría estar contaminada con heces de roedores y caninos observados en los alrededores, así como de heces humanas, dada la situación de infraestructura del zoocriadero.

Se tomaron muestras de heces a todas las tortugas por medio de hisopado rectal estéril y se llevaron a la Estación Experimental IVITA-Iquitos, donde se colocaron en el medio de enriquecimiento Agar Tripticasa de Soya. De allí se enviaron bajo refrigeración (4-6 ${ }^{\circ} \mathrm{C}$ ) al Laboratorio de Bacteriología de la Facultad de Medicina Veterinaria, Universidad Nacional Mayor de San Marcos, Lima.

El cultivo e identificación de Salmonella sp. se llevó a cabo siguiendo los protocolos descritos por la FDA (1995). Se utilizó caldos de enriquecimiento como el Caldo Rappaport, Caldo Tetrationato y Caldo Selenito, y placas de agar Salmonella Shigella (SS), agar Verde Brillante (VB) y agar Xilosa Lisina Desoxicolato (XLD). Se identificó a las bacterias por sus características metabólicas mediante pruebas bioquímicas utilizando el medio SIM, Agar TSI (Hierro Tres Azúcares), Agar Citrato de Simonns, Agar Lisina, Caldo Urea; además del reactivo de Kovacs para la determinación de la producción de Indol. Asimismo, se realizó la identificación con antisueros 
polivalentes (DIFCO Salmonella H Antiserum $\mathrm{a}-\mathrm{z}$ ). La determinación del serotipo y biotipificación, de las cepas se realizó en el Instituto Nacional de Salud, utilizando el método Who Global Salm Surv (Instituto Nacional de Salud, 2007).

Se consideraron como especies de Salmonella a las bacterias positivas a glucosa, producción de gas, y $\mathrm{H}_{2} \mathrm{~S}$, movilidad, citrato, lisina, crecimiento de colonias negras en SS y rodeadas de un halo rosado en agar XLD, y con crecimiento de colonias rojas en agar VB, así como negativas a lactosa, sacarosa, indol, y urea.

Los resultados evidenciaron el aislamiento de dos muestras positivas a Salmonella sp. en las 30 tortugas (6.7\%). Adicionalmente, se encontró otros patógenos en la población de tortugas como Escherichia coli y Pseudomona aeruginosa en el 80\%, Proteus vulgaris en el $26.6 \%$, Citrobacter sp. en el $16.7 \%$, y Proteus mirabilis en el $6.7 \%$.

La temperatura cloacal al inicio de la evaluación varió entre 26 y $32^{\circ} \mathrm{C}$ y la temperatura ambiental estuvo entre 27 a $38^{\circ} \mathrm{C}$. Las dos muestras positivas a Salmonella sp. correspondieron a dos animales con problemas de salud. Estos animales fueron los machos jóvenes, y presentaron heces ligeramente sueltas y con temperatura cloacal de 30 y $32{ }^{\circ} \mathrm{C}$, valores por encima del rango normal para la especie. Asimismo, habían mostrado inapetencia en los últimos días y se desplazaban muy poco en comparación a las demás tortugas.

El análisis de tipificación señaló que era la Salmonella enterica subespecie enterica serotipo typhimurium. Este serotipo ha sido reportado en casos de salmonelosis en humanos (Pasmans et al., 2000), donde provoca un cuadro de enterocolitis con diarreas, nauseas, cefaleas y vómitos (Brooks et al., 1999). Los serotipos del Salmonella typhimurium poseen un amplio rango de hospedadores y pueden infectar a mamíferos, aves y reptiles, siendo el contagio de tipo fecal-oral (Quinn et al., 2004).
La presencia de Salmonella sp. en el $6.7 \%$ de las tortugas motelo fue menor de lo esperado en comparación a otros estudios similares, donde poblaciones de tortugas terrestres presentaron porcentajes superiores al 10\% (Corsalini, 1975) e incluso niveles de 79\% en tortugas terrestres Testudo graeca y Testudo hermani (Pasmans et al., 2000). Sin embargo, Geue y Loschner (2002) reportaron niveles bajos de salmonella en tortugas en comparación con lagartos y serpientes.

\section{LiTERATURA Citada}

1. Bradley T, Angulo F, Mitchell M. 2001. Public veterinary medicine: Public health education on Salmonella spp and reptiles. J Am Vet Med Assoc 219: 745755.

2. Brooks G Morse S, Butel J. 1999. Microbiología médica de Jawetz, Melnick y Adelberg. México: El Manual Moderno. 677 p.

3. Corrente M, Madio A, Friedrich $K$, Greco G, Desario C, Tagliabue S, Incau M, et al. 2004. Isolation of Salmonella strains from reptile faeces and comparison of difference culture media. J Appl Microbiol 96: 709-715.

4. Corsalini T. 1975. Ricerche sulla frequenza delle salmonelle nelle tartarughe della provincia di Foggia (Testudo hermanni). Atti Soc Italiana Scie Vet 29: 624-627.

5. [FDA] Food and Drug Administration. 1995. Bacteriological analytical manual. $8^{\text {th }}$ ed. USA: AOAC International.

6. Geue L, Loschner U. 2002. Salmonella enterica in reptiles of German and Austrian origin. Vet Microbiol 84: 79-91.

7. Hidalgo Vila $J$, Díaz Paniagua $C$, de Frutos Escobar C, Jiménez Martínez C, Pérez Santigosa N. 2007. Salmonella in free living terrestrial and aquatic turtles. Vet Microbiol 119: 311-315. 
8. Monzón C, Ojeda M, Echeita A, Usera M. 1995. Occurrence of Salmonella in cold-blooded animals in Gran Canaria, Canari Islands, Spain. A Van Leeuw 68: 191-194.

9. Pasmans F, De Herdt P, ChasseurLibotte M, Ballasina D, Haesebrouck F. 2000. Occurrence of Salmonella in tortoises in a rescue centre in Italy. Vet Rec 146: 256-258.

10. Pasmans F, De Herdt P, Haesebrouck F. 2002. Presence of Salmonella infection in freshwater turtles. Vet Rec 150: 692-693.

11. Pasmans F, Van Immerseel F, Van den Broeck W, Bottreau E, Velge P, Ducatelle R, Haesebrouck F. 2003. Interactions of Salmonella enterica subsp. enterica serovar Muenchen with Intestinal Explants of the Turtle Trachemys scripta scripta. J Comp Pathol 128: 119-126.
12. Quinn P, Markey B, Cartel M, Donnelly W, Leonard F. 2004. Microbiología y enfermedades infecciosas veterinarias. España: Acribia. 667 p.

13. Strohl P, Tilly B, Fremy S, Brisabois A, Guerin-Faublée V. 2004. Presence of Salmonella in reptiles and amphibians in Spain. Vet Rec 154: 56-58.

14. Instituto Nacional de Salud. 2007. Who Global Salm Surv. Manual de Procedimientos Diagnóstico y caracterización de Salmonella sp. [Internet], (10 junio 2007). Disponible en: http:// www.panalimentos.org/salmsurv/file/ manuales/Manual\%20Salmonella\%20102-07.pdf

15. Wray C, McLaren I, Carrol P. 1993. Escherichia coli isolated from farm animals in England and Wales Between 1986 and1991. Vet Rec 133: 420-439. 